\title{
Transporte, uso e ocupação na cidade de Petrópolis, RJ, Brasil*
}

\section{Transportation, use and occupation in the city of Petrópolis, RJ, Brazil}

\section{Diana Scabelo da Costa Pereira da Silva Lemos}

Doutora em Ciências, no Programa de Engenharia de Transporte,

Universidade Federal do Rio de Janeiro

Pesquisadora de Pós-doutorado no IPPUR, Universidade Federal do Rio de Janeiro, Brasil

https://orcid.org/0000-0001-7642-561X diana.scabelo@gmail.com

\section{Licínio da Silva Portugal}

Programa de Engenharia de Transporte, Universidade Federal do Rio de Janeiro, Brasil

http://orcid.org/0000-0003-4721-114X

licinio@pet.coppe.ufrj.br

\section{Ronaldo Balassiano}

Programa de Engenharia de Transporte, Universidade Federal do Rio de Janeiro, Brasil

https://orcid.org/0000-0003-2500-8685 ronaldo@pet.coppe.ufrj.br

Fecha de recepción: 30 de marzo del 2018 Fecha de aceptación: 6 de junio del 2018 Disponible en línea: 27 de junio del 2018

Sugerencia de citación: Scabelo, D., da Silva Portugal, L. y Balassiano, R. (2018). Transporte, uso e ocupação na cidade de Petrópolis, RJ, Brasil. tiempo\&economía, 5(2), 107-133

* Agradecimento ao Professor Márcio Peixoto de Sequeira Santos (em memória), pela orientação da tese na qual foi desenvolvido este trabalho e ao CNPQ pela concessão de bolsa de doutorado e de pós-doutorado. 


\title{
RESUMO
}

Objetiva-se analisar a distribuição do sistema de transporte e a dinâmica de ocupação municipal na cidade Imperial de Petrópolis, localizada no Estado do Rio de Janeiro, Brasil. Parte-se da premissa de que a acessibilidade representa um elemento chave para propiciar a igualdade espacial na distribuição das oportunidades que um território dispõe a seu favor. A verificação da distribuição desigual da acessibilidade em trabalhos elaborados nas cidades brasileiras reforça a necessidade da sua avaliação no âmbito municipal. A metodologia é constituída de revisão conceitual, de elaboração e processamento dos dados, de elaboração de mapas temáticos e na avaliação do comportamento dos indicadores de acessibilidade. Os resultados ora indicam uma distribuição equitativa, ora demonstram a consolidação de um padrão de desenvolvimento desigual do território, evidenciando a complexidade da sua avaliação.

Palabras clave: transporte, uso, ocupação, acessibilidade e Petrópolis, história econômica

Códigos JEL: D63, O18, R12, R14

\begin{abstract}
The objective of this study is to analyze the distribution of the transportation system and the dynamics of municipal occupation in the Imperial city of Petropolis, located in the State of Rio de Janeiro, Brazil. The premise is that accessibility is a key element in fostering quality in the distribution of the opportunities that a territory has in its favor. The verification of the unequal distribution of accessibility in works developed in Brazilian cities reinforces the need for its evaluation at the municipal level. The methodology consists of conceptual review, elaboration and processing of data, preparation of thematic maps and evaluation of the behavior of accessibility indicators. The results now indicate an equitable distribution, or demonstrate the consolidation of a pattern of unequal development of the territory, evidencing the complexity of its evaluation.
\end{abstract}

Keywords: transportation, use, occupation, accessibility, Petropolis, economic history

JEL Codes: D63, O18, R12, R14 


\section{Introdução e contexto}

Parte-se do problema empírico da distribuição espacial desigual da acessibilidade proveniente da oferta do sistema de transporte e da facilidade de acesso às atividades do uso do solo, nas cidades brasileiras, quando segundo Vasconcellos (2000) a igualdade representa a equalização de uma oferta.

O autor evidencia que o planejamento de transporte contribuiu para a consolidação do padrão de segregação espacial da cidade do Rio de Janeiro, no período de 1870 a 1902, revelando uma dicotomia entre o núcleo e a periferia, que já se esboçava antes mesmo deste período.

Cunha et al. (2004), ao medir a acessibilidade de uma área central do Recife, verifica que a área central dispunha de maior acessibilidade em relação a todas as outras, para viagens de carros por motivo de trabalho.

Henrique e Loureiro (2005), ao analisarem espacialmente a acessibilidade dos usuários do sistema integrado de transportes da cidade de Fortaleza, Brasil, constataram a existência de três grandes regiões de baixa acessibilidade locacional localizadas na área periférica da cidade, considerando-se a cobertura da rede em relação à distância de caminhada para acessar o sistema.

Pretende-se, além de caracterizar o sistema de transporte e a dinâmica de uso e ocupação do solo, compreender no contexto da segregação espacial como estes elementos contribuem para diminuir ou agravar este processo na cidade de Petrópolis, a partir da análise de mapas temáticos.

Como objetivos específicos são almejados a caracterização de/o:

- Conceito e dos indicadores de acessibilidade, através da revisão da literatura.

- Sistema de transporte e da dinâmica de uso e ocupação do solo, através da elaboração de mapas.

- Comportamento dos indicadores de acessibilidade, através de sua aplicação e normalização.

O conceito da acessibilidade é adotado metodologicamente, porque existe um consenso na literatura de que este representa um benefício territorial (Santos, 1990; Cunha et al., 2004; Sanches et al., 2007).

Parte-se do pressuposto que a interdependência entre a rede do sistema de transporte e o uso e a ocupação do solo afeta a acessibilidade. A análise somente do transporte ou somente do uso e da ocupação do solo é inadequada ou insuficiente para o planejamento da cidade, porque uma mudança no uso do solo afeta o transporte, tal como o transporte interfere no uso e na ocupação do solo, revelando a necessidade de um planejamento interdependente destes dois elementos que usualmente, são analisados, planejados e projetados de forma independente.

No relatório Buchanan (1961 apud Delgado, 2002), a circulação foi apresentada como função das atividades do uso do solo. Segundo Litman (2007) nas análises de acessibilidade se reconhece que o uso do solo tem impacto considerável sobre o transporte.

tiempo\&economía

Vol. 5 N. ${ }^{\circ} 2$ - Julio - Diciembre del 2018 
Sinha e Labi (2007) apontam que a formação do padrão do uso do solo é fortemente influenciada pelo nível de acessibilidade, proveniente da infraestrutura de transporte. A provisão da capacidade de transporte interfere no padrão de distribuição e ocupação do uso que reflete na expansão das novas atividades e no padrão socioeconômico da região. Assim, o processo de isolamento dos efeitos do sistema de transporte no uso do solo e vice versa podem ser bastante complicados.

A cidade de Petrópolis foi selecionada pela sua importância histórica e de sua diversidade ambiental e ecológica. Sua fundação está relacionada ao Imperador D. Pedro I que adquiriu algumas propriedades na região com o intuito de construir um Palácio de Verão. Em 1834, D. Pedro II herda essas terras e Paulo Barbosa retoma os planos de Pedro I e com Köeler, engenheiro alemão, elaboraram um plano para a doação de terras da fazenda imperial a colonos livres, que iriam levantar uma nova povoação e desenvolver atividades agrícolas (IBGE, 2018). ${ }^{1}$

Em 1843, o Imperador, assinou decreto para o projeto e a construção do Palácio Imperial; a urbanização de uma Vila Imperial, a edificação de uma igreja e a construção de um cemitério.

Petrópolis é considerada a primeira cidade planejada do Brasil. O município é composto por um núcleo urbano, chamado de "Quarteirões Imperiais". Koeler batizou os quarteirões com o nome da região, de onde vinham as famílias alemãs, italianas e açorianas (do arquipélago de Açores, localizado em Portugal). Esta configuração perdura até hoje, constituída de um abairramento (ruas agrupadas), segundo a estrutura original.

Petrópolis foi a capital do Estado do Rio de Janeiro, no período de 1894 a 1903, quando a cidade do Rio de Janeiro era a capital federal. Com a transferência da capital federal para Brasília, durante a década de 1970, a cidade do Rio de Janeiro passa a ser a capital do Estado do Rio de Janeiro e Petrópolis reduz sua importância, no contexto político do país. Esta mudança refletiu na sua dinâmica de ocupação. Com base na figura 1, é possível afirmar que esta continuou a crescer até 1984, com um maior adensamento entre 1956 e 1984 e um crescimento reduzido entre 1984 e 1994.

A área urbana de Petrópolis está condicionada à sua topografia, constituída de um relevo montanhoso, cuja ocupação margeia o seu eixo viário. Seu principal acesso intermunicipal é pela BR-040 (ligação ao sul com Duque de Caxias e com o Rio de Janeiro e ao norte com Areal). A BR-495 faz a ligação entre Petrópolis e Teresópolis. A BR-493 faz a ligação do município com Paty do Alferes (figura 2).

A metodologia deste trabalho é constituída de cinco etapas, dentre elas:

1. Revisão do conceito de acessibilidade e formulação de indicadores de acessibilidade compostos.

2. Pesquisa de dados e elaboração de um banco de dados.

3. Definição de um zoneamento municipal.

4. Aplicação e avaliação do comportamento dos indicadores de acessibilidade.

5. Elaboração de mapas.

1 Nos anos de 1800 chegaram os imigrantes alemães à Petrópolis (IBGE, 2018). 
Para compatibilizar e converter as informações obtidas nas diferentes base de dados, adotou-se o Arcgis/ Arcview 9.3 (SIG da empresa ESRI) que permite a importação do Transcad 4.5 (SIG), do Autocad (empresa Caliper) e do Microsoft Excel.

Figura 1. Dinâmica de ocupação do município de Petrópolis

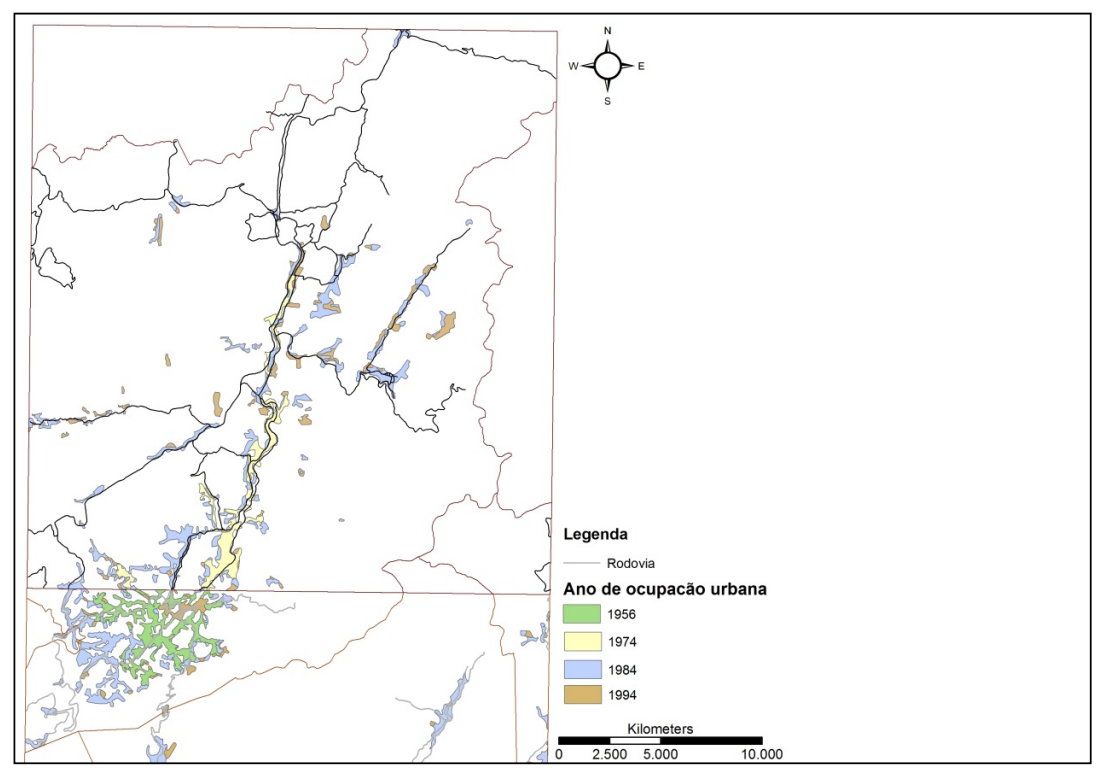

Fonte: elaboração própria, com base em CEPERJ (2010)

Figura 2. Representação em 3D da topografia do município de Petrópolis

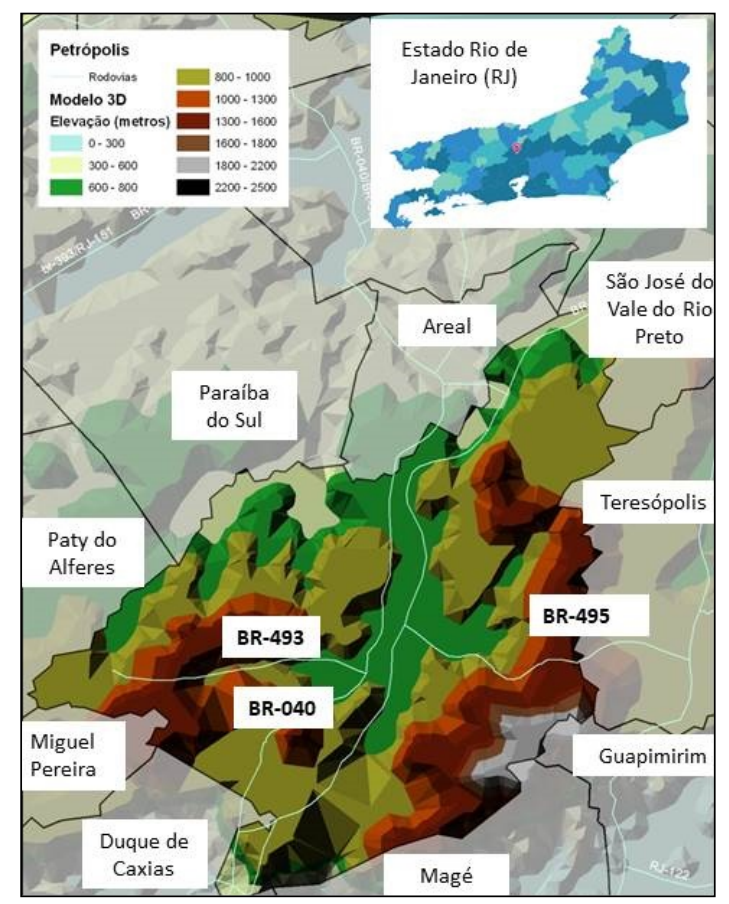

Fonte: elaboração própria a partir da Base Integrada ao Milionésimo (IBGE 2004) 
O sistema viário de Petrópolis é constituído de vias de circulação, de calçadas, de linhas de ônibus, de pontos de ônibus e de terminais de ônibus. Quanto ao sistema viário, estão sendo consideradas as informações gráficas em coordenadas vetoriais, com topologia arco nó, associada a uma rede linear conectada. Os arcos incluem o sentido de fluxo e os diferentes atributos relacionados ao nível de serviço da via e ao transporte não motorizado, as calçadas. Em relação ao transporte público foram analisados os dados das rotas das linhas de transporte coletivo (figura 3), o número de viagens da primeira e da última viagem (CPTRANS, 2010), assim como os terminais de transporte. Esta pesquisa foi sistematizada em 2010; contudo, em 2018, procedeu-se à conferência dos dados, considerando que esta parte do sistema de transporte é flexível e pode ser alterada com maior facilidade em relação à oferta viária e às atividades do uso do solo.

Em relação às rotas, aproximadamente $6,25 \%$ do total de linhas foi acrescida entre $2010 \mathrm{e}$ 2018, indicando percentual pouco significativo. Quanto às frequências, foram realizadas pequenas alterações nos horários iniciais e finais de disponibilidade do atendimento (no máximo em torno de 30 minutos), ora para mais ou para menos, não alterando significativamente os resultados alcançados para este indicador. Evidencia-se, portanto, percentualmente a validade atual dos resultados alcançados.

Para caracterização da dinâmica de uso e ocupação do solo, estão sendo contempladas as atividades de estabelecimentos de ensino (públicos e particulares), de saúde pública, de hospedagem, de serviços, comerciais, industriais, os hospitais públicos, os postos de saúde e as agências bancárias.

A estrutura administrativa municipal de Petrópolis possui cinco distritos: Petrópolis $\left(1^{\circ}\right)$, Cascatinha $\left(2^{\circ}\right)$, Itaipava $\left(3^{\circ}\right)$, Pedro do Rio $\left(4^{\circ}\right)$ e Posse $\left(5^{\circ}\right)$. Como o município não dispõe de regiões administrativas internas abrangendo toda a sua superfície, para a aplicação desta metodologia, foi necessário definir um zoneamento na etapa metodológica três. O zoneamento é composto por unidades espaciais de análise -UEA- partindo-se da premissa do agrupamento dos setores censitários, considerando o número de habitantes por setor censitário como variável principal. O resultado consistiu num zoneamento constituído de sessenta e cinco unidades espaciais de análise, para os cinco distritos da cidade de Petrópolis, para as quais foram definidos os seus nós para estimativa das distâncias entre estas unidades (figura 3).

$\mathrm{Na}$ etapa quatro, foram aplicados e normalizados os indicadores de acessibilidade na cidade e na etapa cinco foram elaborados mapas temáticos.

Este trabalho está estruturado em três partes. Na primeira, é apresentada a revisão da literatura da acessibilidade, comtemplando sua conceituação e uma classificação de seus indicadores. Na segunda, é exibida a caracterização do sistema de transporte e da sua dinâmica de ocupação municipal da cidade de Petrópolis. E na terceira, é possível observar o comportamento dos indicadores de acessibilidade. 
Figura 3. Delimitação das unidades espaciais de análise e definição dos seus nós, a partir do seu sistema viário estruturante

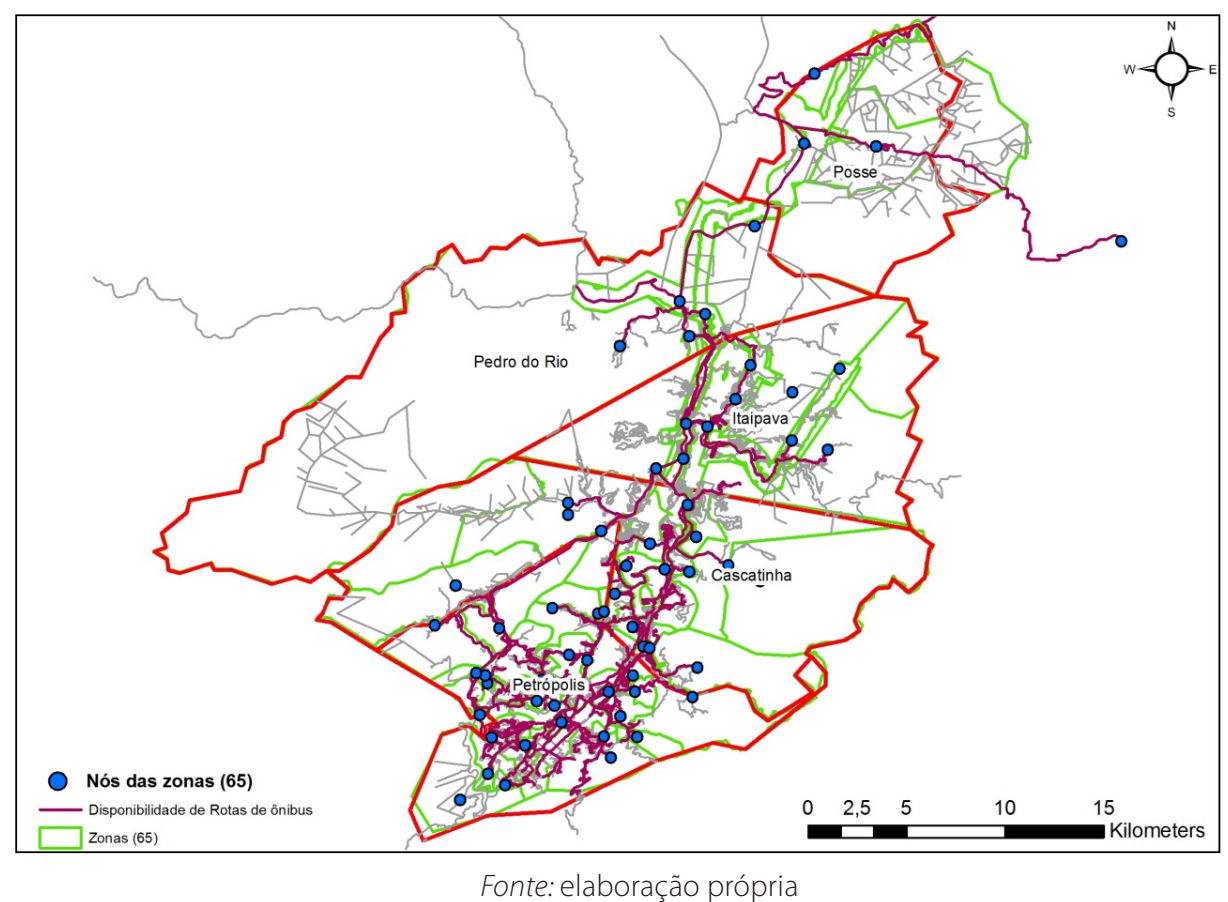

\section{A acessibilidade: conceituação e classificação dos indicadores}

A acessibilidade vem sendo conceituada desde 1826 (trabalho de Von Thunen), segundo Raia Jr. (2000).

A principal conceituação de acessibilidade foi estabelecida por Hansen (1959 apud Sales Filho), como o potencial de interação entre atividades e como medida da distribuição espacial das atividades, em relação a um ponto, ajustadas à habilidade e desejo das pessoas ou firmas em superar a separação espacial. Observa-se que as abordagens de acessibilidade posteriores (Cunha et al., 2004; Karst e Wew, 2004; Henrique e Loureiro, 2005 e Litman, 2007), reafirmam o seu conceito de potencial de deslocamento.

Não obstante a posterior introdução de diversos aprimoramentos permanece ainda hoje os princípios básicos da formulação proposta por Hansen.

A acessibilidade é conceituada, também, como a capacidade ou facilidade com a qual as atividades do uso do solo podem ser alcançadas, utilizando-se um determinado modo de transporte, segundo abordagens mais recentes tais como Raia Jr. (2000), Vasconcellos (2000), Fundação COPPETEC (2006), Ferronatto e Michel (2007), Litman (2007) e segundo referências anteriores que podem ser verificadas no trabalho de Sales Filho (1996).

Litman (2007) caracteriza a acessibilidade como a facilidade de se alcançar bens, serviços, atividades e destinos que de forma associada são chamados de oportunidades, geralmente interpretadas através do sistema de transporte. Pode ser ainda, definida como o potencial para interação e troca. A acessibilidade pode ser definida, em termos de potencial de oportunidades que podem ser alcançadas, ou em termos de atividades acessadas. 
Na revisão da literatura, observa-se que os fatores que afetam a acessibilidade estão agrupados em dois grupos: a rede do sistema de transporte e a organização espacial das atividades do uso do solo.

A rede de transporte como elemento que caracteriza o conceito de acessibilidade é evidenciado através das abordagens de Hansen (1959), Ingram (1971 apud Sales Filho), Souza (1990), Sales Filho (1996), Pires (2000), Raia Jr (2000), Vasconcellos (2000), Halden (2002), Cunha et al. (2004), Karst e Wee (2004), Pasaogullari e Doratli (2004), Bertolini et al. (2005), Henrique e Loureiro (2005), Puebla e Melhorado (2006), Fundação COPPETEC (2006), Ferronato e Michel (2007) e Litman (2007).

De acordo com Vasconcellos (2000), a rede do sistema de transportes é definida pela infraestrutura de circulação, constituída por ruas, calçadas, vias férreas e terminais e pela infraestrutura do transporte público, tais como os veículos que farão o transporte, a estrutura das linhas e a frequência das viagens.

Karst e Wee (2004) identificam que o uso do solo influencia o resultado da acessibilidade, ao refletir a quantidade da distribuição espacial das oportunidades ofertadas em cada destino, tais como empregos, salas comerciais, empreendimentos de saúde, sociais e recreacionais em relação à sua origem (áreas residenciais). De acordo com Olaru (2005), a própria organização das atividades acessíveis influencia a acessibilidade.

As atividades provenientes do uso do solo definidas no planejamento municipal (tipo e distribuição espacial) são citadas como elementos pertinentes à acessibilidade com base na revisão de: Sales Filho (1996), Goto (2000), Pires (2000), Raia Jr (2000), Vasconcellos (2000), Halden (2002), Cunha et al. (2004), Karst e Wee (2004), Pasaogullari e Doratli (2004), Bertolini et al. (2005), Pegoreti e Sanches (2005), Puebla e Melhorado (2006), Fundação COPPETEC (2006), Ferronato e Michel (2007) e Litman (2007).

A organização espacial da cidade é proveniente da localização e do agrupamento dos diferentes tipos de atividades, envolvendo o uso e a ocupação do solo (Vasconcellos, 2000).

Em resumo, são quatro os elementos que caracterizam a acessibilidade: o sistema viário (a rede, o nível de serviço, etc), o transporte coletivo (a estrutura das linhas e a frequência), o transporte não motorizado (ciclovias e calçadas) e o uso e a ocupação do solo (tipo de uso, agrupamento das atividades). Almeja-se abordar todos estes elementos na análise do sistema de transporte e da dinâmica de ocupação da cidade de Petrópolis.

Os indicadores de acessibilidade podem ser classificados em seis medidas, ora em função, dos fatores e dos elementos da acessibilidade, ora em função da medida em si, dentre elas:

1. Indicadores de topologia da rede: traduzem o comportamento e os atributos da rede do sistema viário.

2. Acessibilidade global: permite avaliar a separação espacial entre dois pontos (ou mais) localizados no território.

3. Indicadores de infraestrutura e nível de serviço do sistema de transporte: refletem a disponibilidade e a qualidade do sistema viário, do transporte coletivo e do transporte não motorizado. 
4. Medidas de contorno: medem as curvas de oportunidades acumuladas e relação às atividades do uso do solo.

5. Acessibilidade gravitacional: representa o potencial de deslocamento às oportunidades almejadas.

6. Medidas de organização das atividades do uso do solo: refletem a distribuição das atividades do uso do solo.

Na terceira parte deste trabalho estão sendo utilizados indicadores compostos pelos autores e derivados das formulações originais das medidas de indicadores de infraestrutura e nível de serviço do sistema de transporte, de acessibilidade global e medidas de organização das atividades do uso do solo. O conceito de cada um deles estará sendo abordado no tópico seguinte.

As vantagens dos indicadores de infraestrutura e nível de serviço do sistema de transporte são disponibilidade de dados, facilidade de compreensão dos resultados. Permitem, ainda, avaliar as condições do transporte viário, coletivo e do não motorizado, estando orientado às diversas perspectivas de análise, tais como o deslocamento de veículo, de passageiro, do pedestre, do ciclista e do território. A vantagem da acessibilidade global consiste na necessidade reduzida de dados, permitindo analisar a impedância de deslocamento. Já a vantagem das medidas de organização das atividades do uso do solo está em traduzir a relação de dependência espacial entre transporte e uso do solo. Todas as três medidas apresentam Simplicidade de cálculo.

\section{Petrópolis: sistema de transporte e ocupação municipal}

O sistema viário de Petrópolis é caracterizado pela sua hierarquia, classificada em vias expressas, arteriais, coletoras e locais (figura 4). A hierarquização adotada se assemelha à de Hutchinson (1979). Segundo o autor, a via expressa dispõe de grande volume de tráfego, correspondendo às rodovias que conectam o município com o vizinho. A arterial representa eixo de ligação de bairros e de distritos. A coletora distribui o fluxo de trânsito até ou a partir das vias principais. Tanto a coletora quanto a via local contribuem para a integração da via com as atividades do uso do solo.

Os principais meios de transporte de pessoas no município consistem no carro, na moto e no ônibus. Uma característica, marcante do município, consiste no crescimento da sua frota de veículos. Entre 2002 e 2008, a taxa de crescimento da frota de motos e motonetas foi de $103 \%$ e entre 2002 e 2016 , de $198 \%$, sendo também expressivo o crescimento da frota de carros entre 2002 e 2016 , de $53 \%$, como pode ser observado na tabela 1 . O crescimento da taxa motorizada por moto ou carro pode ter ocasionado o decréscimo na frota de ônibus, em função da redução da demanda por transporte público, num ciclo difícil de romper, que privilegia o incremento de investimentos na infraestrutura do sistema viário, em detrimento do transporte público.

tiempo\&economía

Vol. 5 N. ${ }^{\circ} 2$ - Julio - Diciembre del 2018 
Figura 4. Hierarquia do sistema viário, do município de Petrópolis

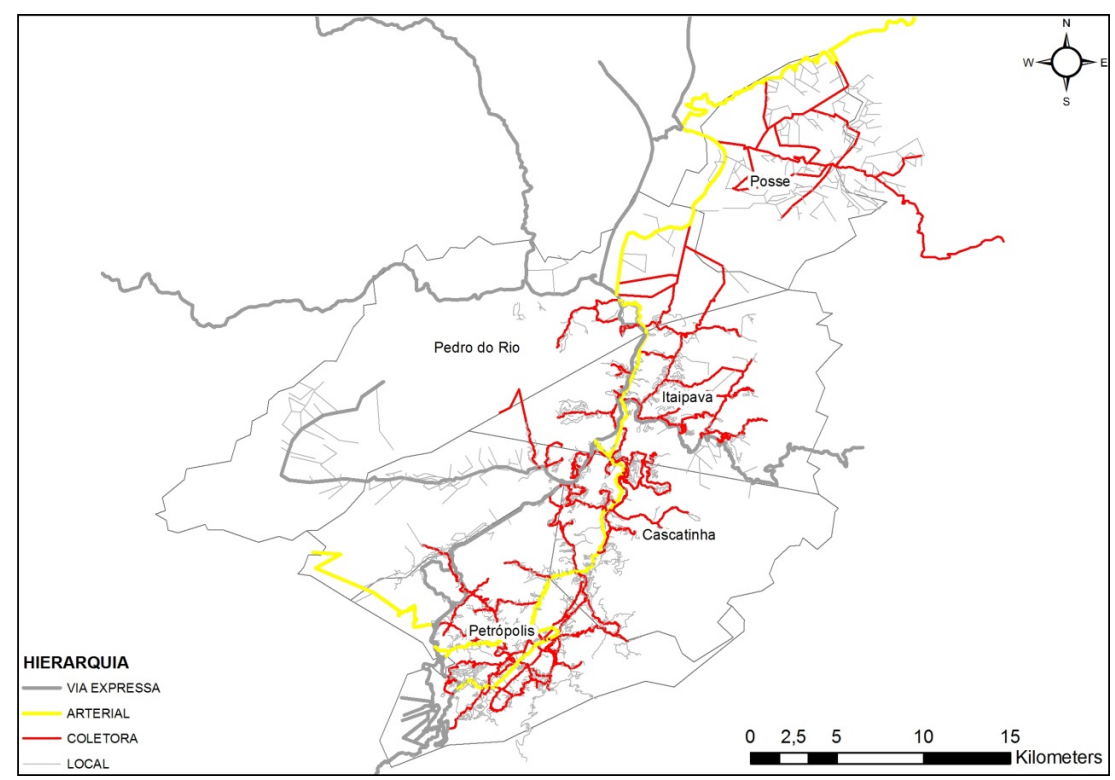

Fonte: elaboração própria em CPTRANS (2010)

Tabela 1. Percentual de crescimento da frota de Petrópolis, entre 2002 e 2016

\begin{tabular}{|c|c|c|c|}
\hline Data & Carro & Moto/ Motoneta & Ônibus/ Micro Ônibus \\
\hline 2002 & 66.711 & 8.626 & 1.121 \\
\hline 2008 & 77.461 & 17.581 & 1.193 \\
\hline 2016 & 102.268 & 25.736 & 998 \\
\hline $\begin{array}{c}\text { Crescimento } \\
2002-2008\end{array}$ & $16 \%$ & $103 \%$ & $6 \%$ \\
\hline $\begin{array}{c}\text { Crescimento } \\
2002-2016\end{array}$ & $53 \%$ & $198 \%$ & $-11 \%$ \\
\hline
\end{tabular}

Fonte: elaboração própria, com base em Governo do Estado do Rio de Janeiro (2003; 2009) e IBGE (2018)

A população da cidade de Petrópolis em 2000 era de 283.746 habitantes (a maior da Região Serrana) (IBGE, 2002; 2018), em 2010, de 295.917 habitantes e atualmente estimada em 2017 em 298.235. O município apresentou, entre 1991 e 2000, uma taxa média de crescimento de $1,28 \%$, ao ano e entre 2000 e 2017, uma taxa estimada de 5,1\%.

Petrópolis, em função da colonização imperial representa um sítio histórico, localizado em sua área central. Nesta, estão localizadas, inúmeras edificações tombadas pelo patrimônio histórico (quase vinte edificações). O tráfego intenso de veículos na área central vem abalando a estrutura deste patrimônio, tanto em função da trepidação, quanto da emissão de gases poluentes. 
Como os distritos de Petrópolis e de Cascatinha representam áreas de preservação ambiental (figura 5), sua legislação municipal condiciona os seus usos. Nestes distritos estão localizados o Parque Nacional da Serra dos Órgãos, a Reserva Biológica de Araras e a Reserva Biológica do Tinguá.

Figura 5. Áreas de Proteção e de Parques Estaduais e Federais em Petrópolis

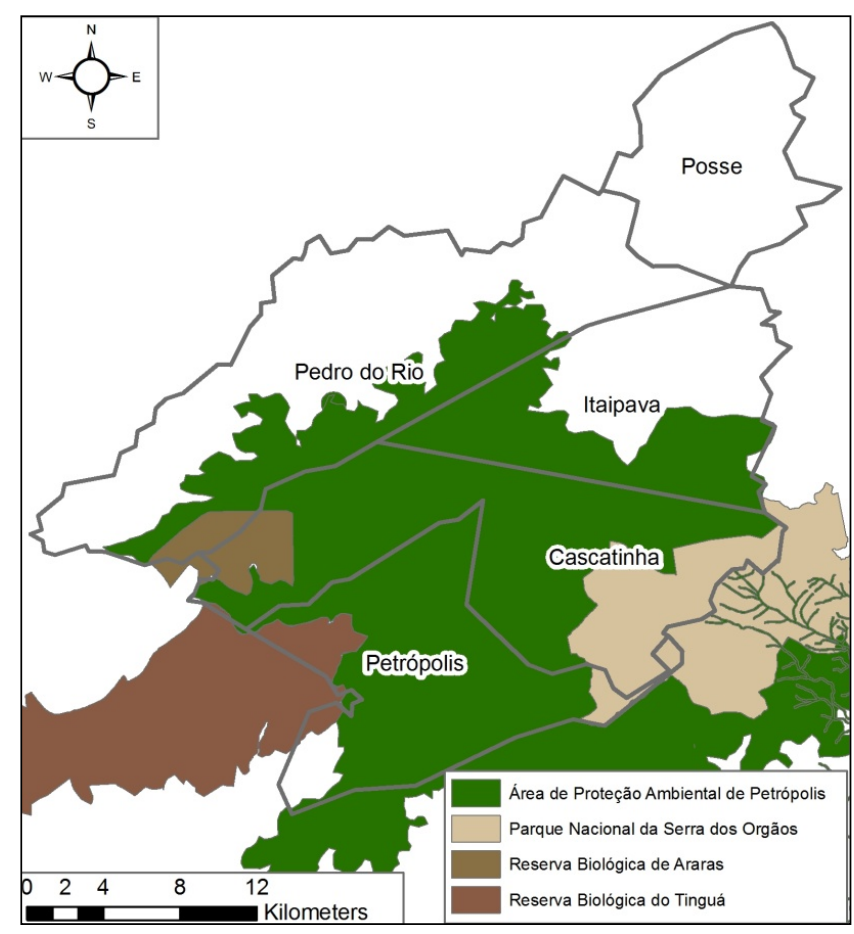

Fonte: elaboração própria, com base em CEPERJ (2010)

Pretende-se avaliar como a distribuição populacional da cidade a partir do Centro (UEA 52). A organização espacial de Petrópolis apresenta uma ocupação do solo que diminui à medida que distância ao centro aumenta (exceto para o intervalo de $41 \mathrm{~km}$ a $51 \mathrm{~km}$ ), cujo número de habitantes volta a crescer, como é possível observar na tabela 2. Percentualmente, $45 \%$ da população residem até $10 \mathrm{~km}$ do Centro, $65 \%$ até $20 \mathrm{~km}$ e somente $34 \%$ habita no intervalo de 21 a $51 \mathrm{~km}$.

Tabela 2. Número de habitantes que residem a um determinado intervalo de distância do Centro

\begin{tabular}{|c|c|}
\hline $\mathbf{N}^{\circ}$ de habitantes & Distância até o centro $(\mathbf{k m})$ \\
\hline 7.765 & 41 a 51 \\
\hline 5.642 & 31 a 40 \\
\hline 12.640 & 21 a 30 \\
\hline 15.694 & 11 a 20 \\
\hline 34.506 & 0 a 10 \\
\hline
\end{tabular}

Fonte: elaboração própria, com base em IBGE (2000) 
Em Petrópolis, os empregos estão concentrados no distrito de Petrópolis, no Centro e Retiro 3 (UEA 52 e 40) como apresentado na figura 6. Os dados relativos aos empregos consistem na localização dos estabelecimentos que mais geram oportunidades de empregos na cidade, tais como os estabelecimentos comerciais e industriais. Constata-se que a configuração linear da cidade e sua ocupação implicam na adoção de meio motorizado para o deslocamento até o distrito de Petrópolis, para acessar as oportunidades de emprego.

As unidades que dispõem de serviços de segurança (figura 7), tais como batalhões do corpo de bombeiro e da polícia militar, são as de Pedro do Rio 1; Itaipava 2; Carangola 2; Cascatinha/ Estrada da Saudade/ Auto da Serra; Quitandinha e Siméria/ Alto da Serra/ Castelânea/ Saldanha Marinho (UEA 6, 12, 28, 31, 58 e 59), localizadas respectivamente nos distritos de Pedro do Rio, Itaipava, Cascatinha e Petrópolis, com uma distribuição descentralizada, presente em quase todos os distritos, contribuição para uma distribuição menos desigual, em relação ao número de empregos.

Figura 6. Principal unidade espacial de análise com potencial disponibilidade de empregos, do município de Petrópolis

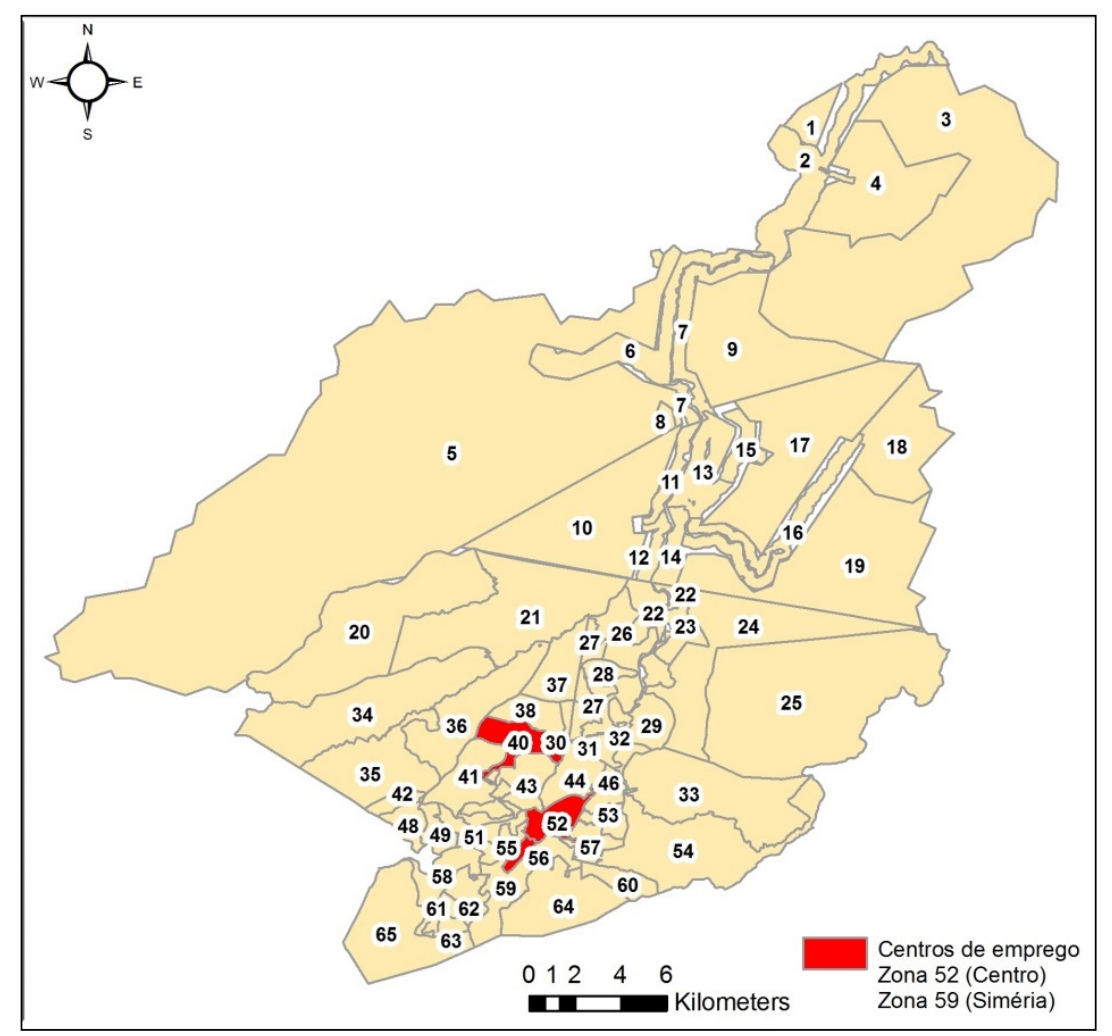


Figura 7. Localização dos serviços de segurança pública civil

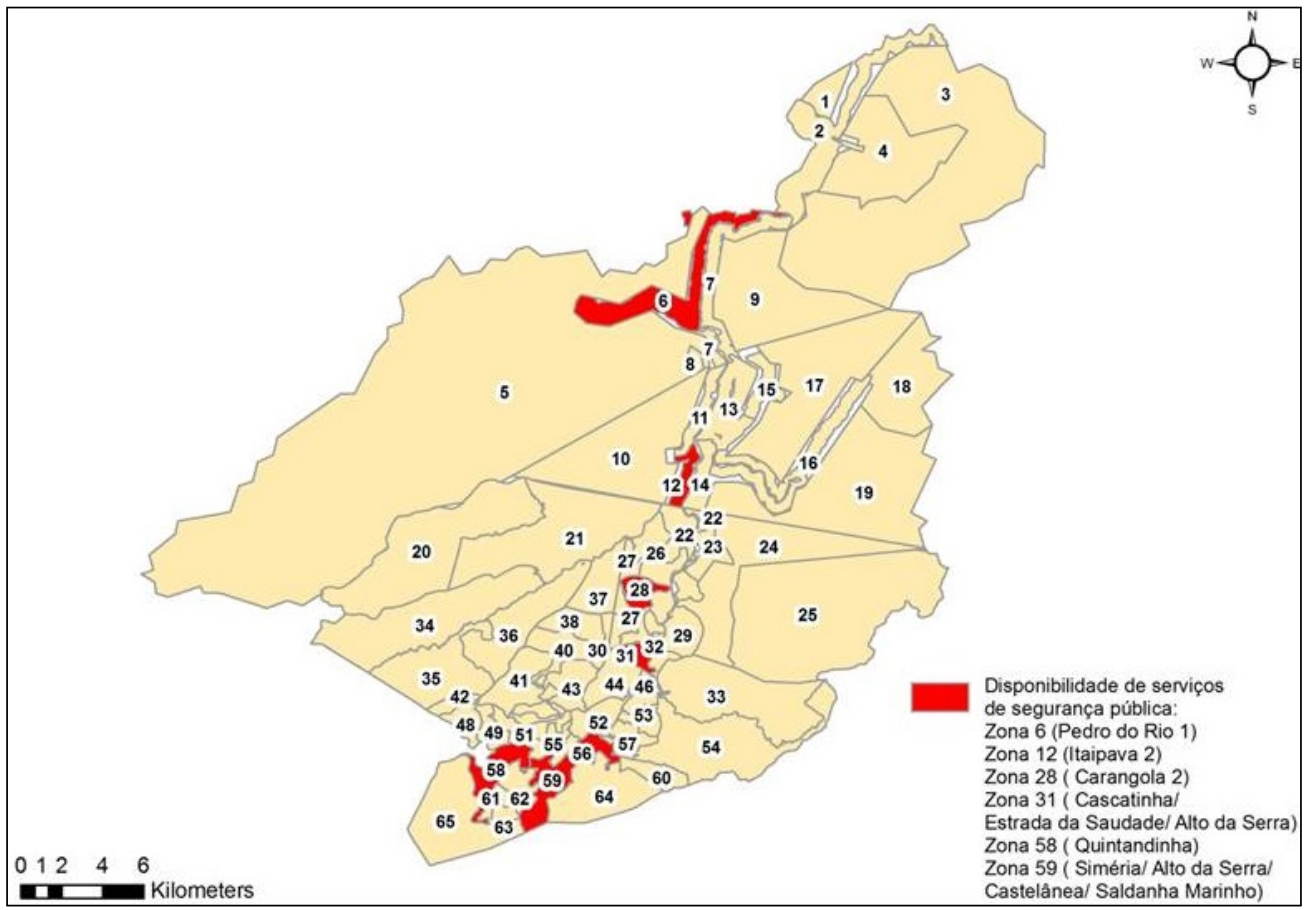

Fontes: elaboração própria com base em Prefeitura Municipal de Petrópolis (2009) e Governo do Estado do Rio de Janeiro (2009)

\section{Petrópolis: o comportamento dos indicadores de acessibilidade}

Objetiva-se avaliar o comportamento do conjunto de onze indicadores para análise da acessibilidade na cidade de Petrópolis, através da normalização dos resultados de cada indicador primário, com base na expressão um.

$$
\text { Normalização }=\frac{\text { Valor atual }- \text { valor mínimo }}{\text { Valor máximo }- \text { valor mínimo }}
$$

O desempenho comparativo é expresso entre zero e um. Adota-se uma classificação por cores, segundo os parâmetros adotados no IDH (tabela 3), em função de sua internacional reconhecida capacidade de analisar, comparativamente, o desenvolvimento humano.

Tabela 3. Classificação do IDH

\begin{tabular}{|c|c|}
\hline Intervalo IDH & Classificação \\
\hline $0,9-1,0$ & Muito Elevado \\
\hline $0,8-0,899$ & Elevado \\
\hline $0,5-0,799$ & Médio \\
\hline $0-0,499$ & Baixo \\
\hline
\end{tabular}

Fonte: elaboração própria com base em PNUD (2009) 
Partiu-se do número de habitantes por unidade espacial (figura 8) e observam-se valores muito elevados nas unidades Siméria/ Alto da Serra/ Castelânea/ Saldanha Marinho, Coronel Veiga/ Val Paraiso e Chácara Flora/ Castelânea/ Alto da Serra (UEA 56, 59 e 64), localizadas no distrito de Petrópolis. O Centro (UEA 52) apresentou valores médios.

Figura 8. Normalização do número de habitantes

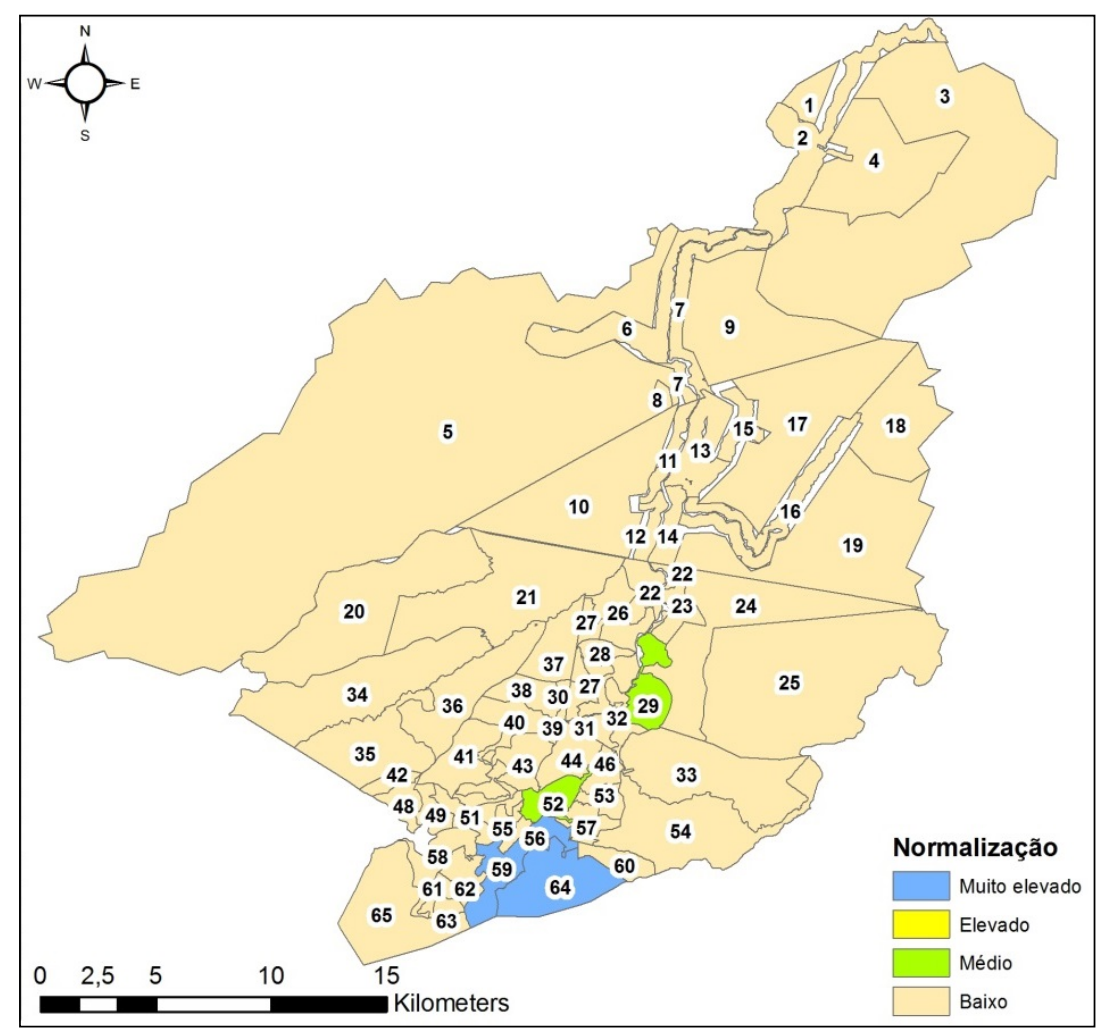

Fonte: elaboração própria com base em IBGE (2000)

O indicador de oferta da extensão viária (figura 9) consiste no somatório de toda a extensão viária de uma UEA pela sua área total. Somente ao longo do sistema viário estruturante da cidade de Petrópolis este indicador apresenta classificação variando de médio, elevado e muito elevado. Em geral, observa-se um desempenho baixo.

O indicador de cobertura espacial viária (figura 10) considera a área da banda (buffer), para os dois lados da via, de $1 \mathrm{~km}$ a partir do eixo da via arterial e de 400m do eixo da via coletora, pela área total de cada unidade espacial. Ao assumir que a oportunidade de utilizar a via se estende ao seu entorno, o indicador de cobertura espacial viário no município demonstra um desempenho muito elevado para um número expressivo de unidades espaciais de análise, em todos os distritos, revelando uma distribuição equitativa do sistema viário em toda a cidade.

O indicador de acessibilidade integral inter-regional (figura 11) é função das distâncias percorridas, através do sistema viário, considerando-se o caminho mínimo e o sentido das vias. Representa o somatório entre uma unidade espacial e todas as outras. Quanto menor o resultado, melhor o seu desempenho. Para este indicador, um número reduzido de unidades 
Figura 9. Normalização da oferta da extensão viária

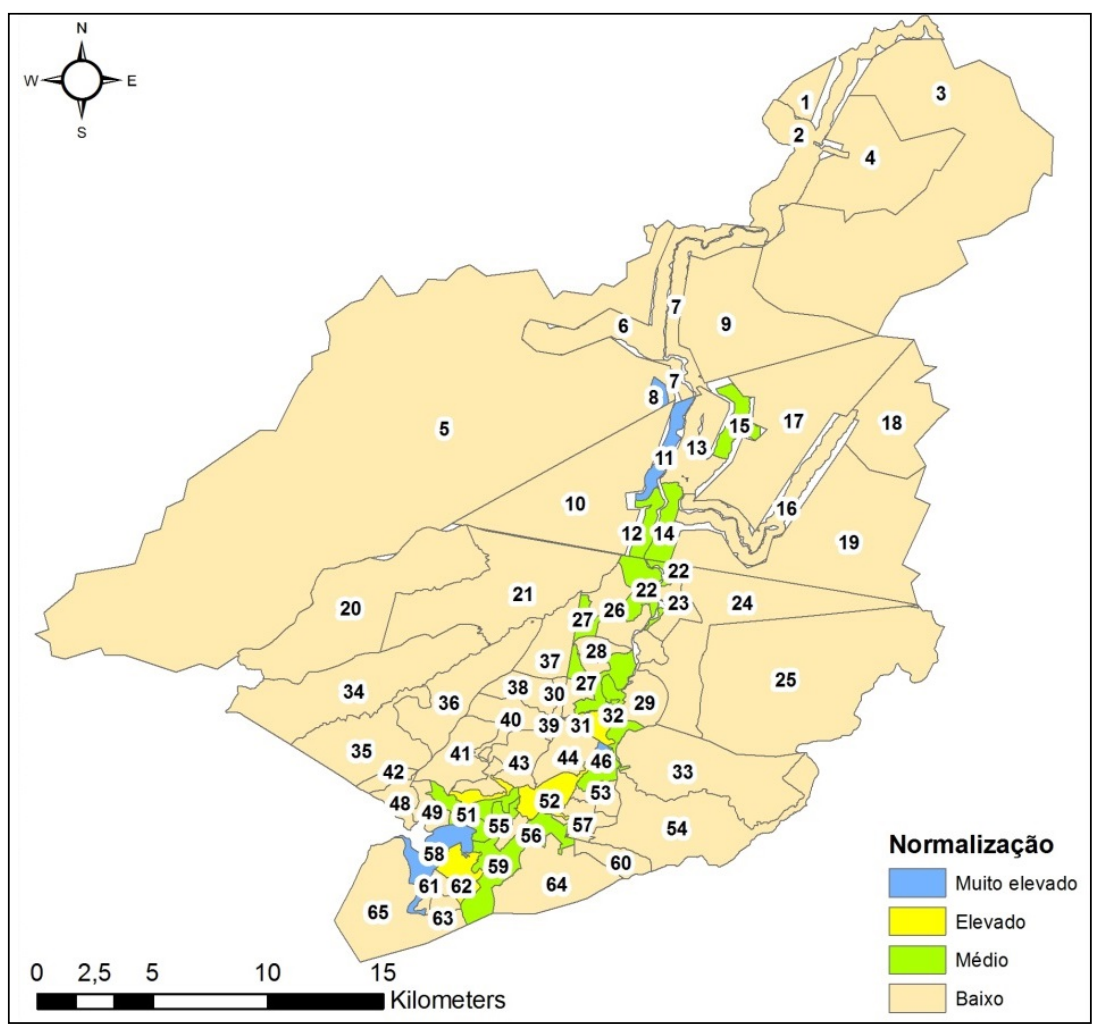

Fonte: elaboração própria

apresenta uma classificação baixa. Este indicador apresenta o melhor desempenho para o sistema viário.

O indicador de oferta da extensão das vias coletoras, com pavimentação de qualquer tipo, exceto terra (figura 12) consiste na divisão da extensão das vias coletoras com asfalto ou com paralelepípedo, pela extensão total das vias coletoras. A classificação para a maioria da unidades espaciais de análise -UEA-, em todos os distritos é muito elevada para este indicador.

Já o indicador de oferta da extensão das vias locais, com pavimentação de qualquer tipo, exceto terra (figura 13) apresenta uma classificação baixa para a maioria da cidade, alternando com uma classificação média na área urbana dos distritos de Petrópolis e Cascatinha. Em suma, as vias locais são constituídas de terra, em geral no município.

O indicador de acessibilidade integral inter-regional (figura 14), proveniente do sistema coletivo é função das distâncias percorridas, através da rede viária, somente nas rotas das linhas de ônibus, de uma UEA, multiplicada pelo número de linhas sobrepostas, pela sua área total. Um número reduzido de unidades apresenta uma classificação baixa, com predominância de uma classificação muito elevada no sistema viário estruturante do município. Este indicador apresenta um excelente desempenho, contribuindo para uma distribuição equitativa das oportunidades para o transporte público. 
Figura 10. Normalização da cobertura espacial viária

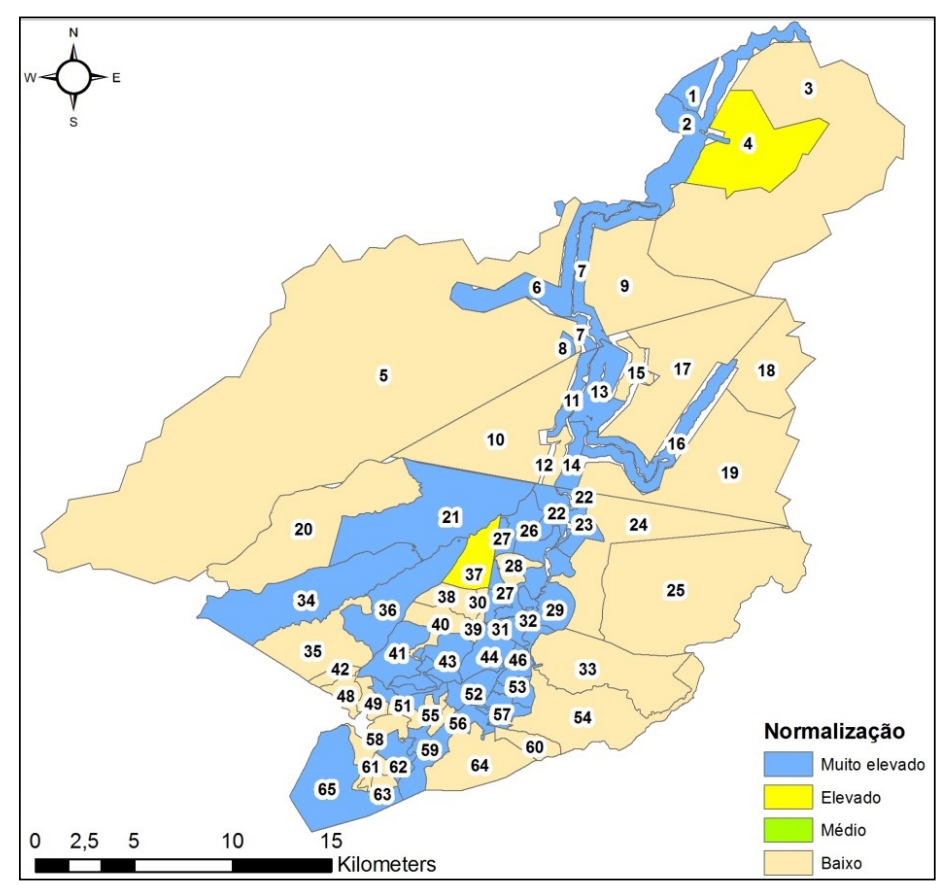

Fonte: elaboração própria

Figura 11. Normalização da acessibilidade integral inter-regional, proveniente do sistema viário

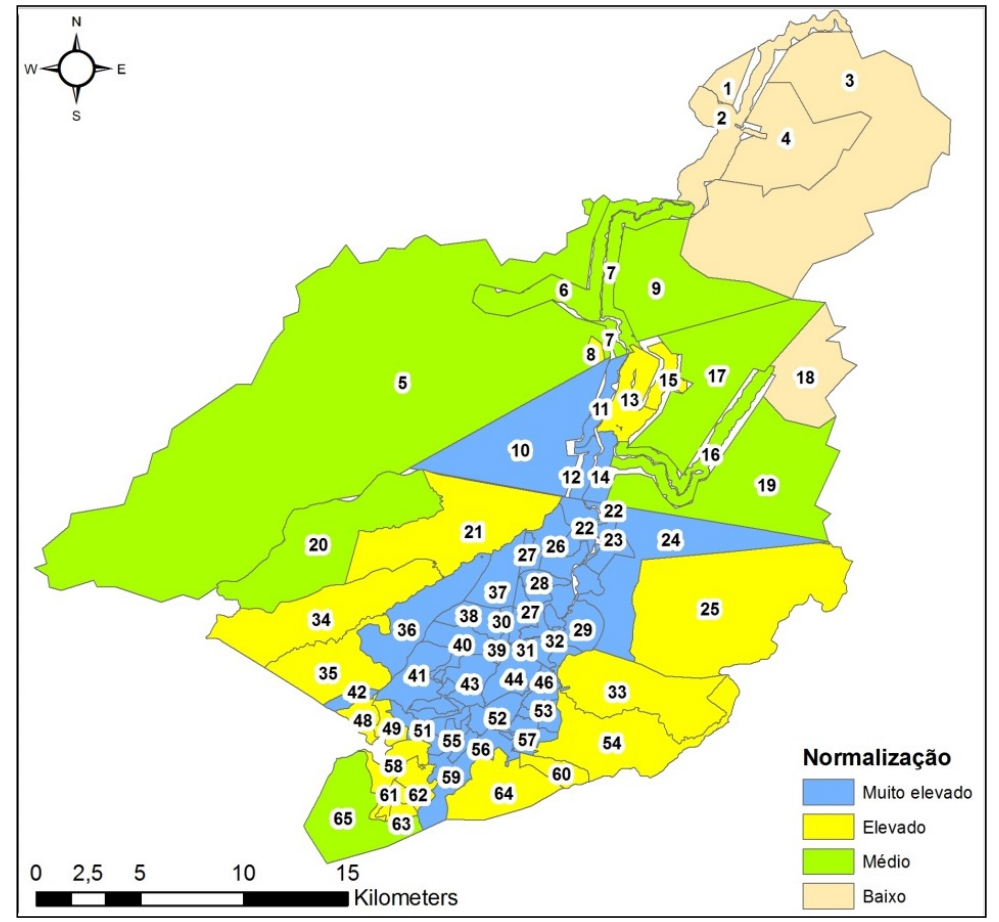

Fonte: elaboração própria 
Figura 12. Normalização da oferta da extensão das vias coletoras, com pavimentação de qualquer tipo, exceto terra

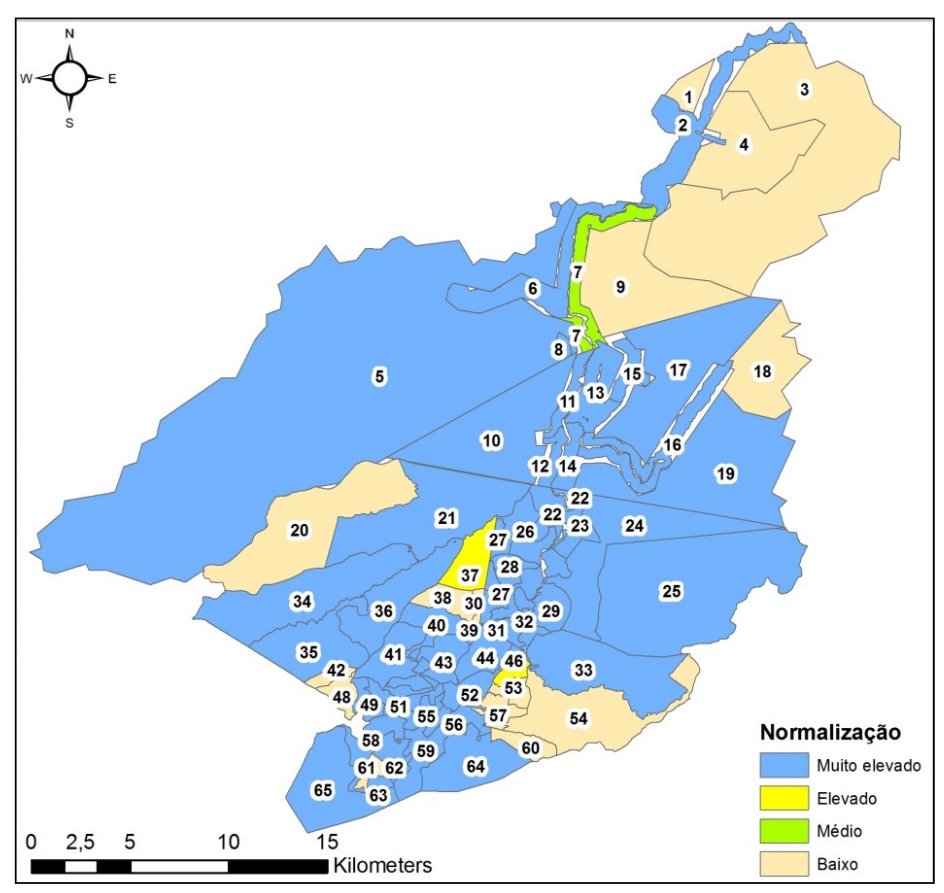

Fonte: elaboração própria

Figura 13. Normalização da oferta da extensão das vias locais, com pavimentação de qualquer tipo, exceto terra

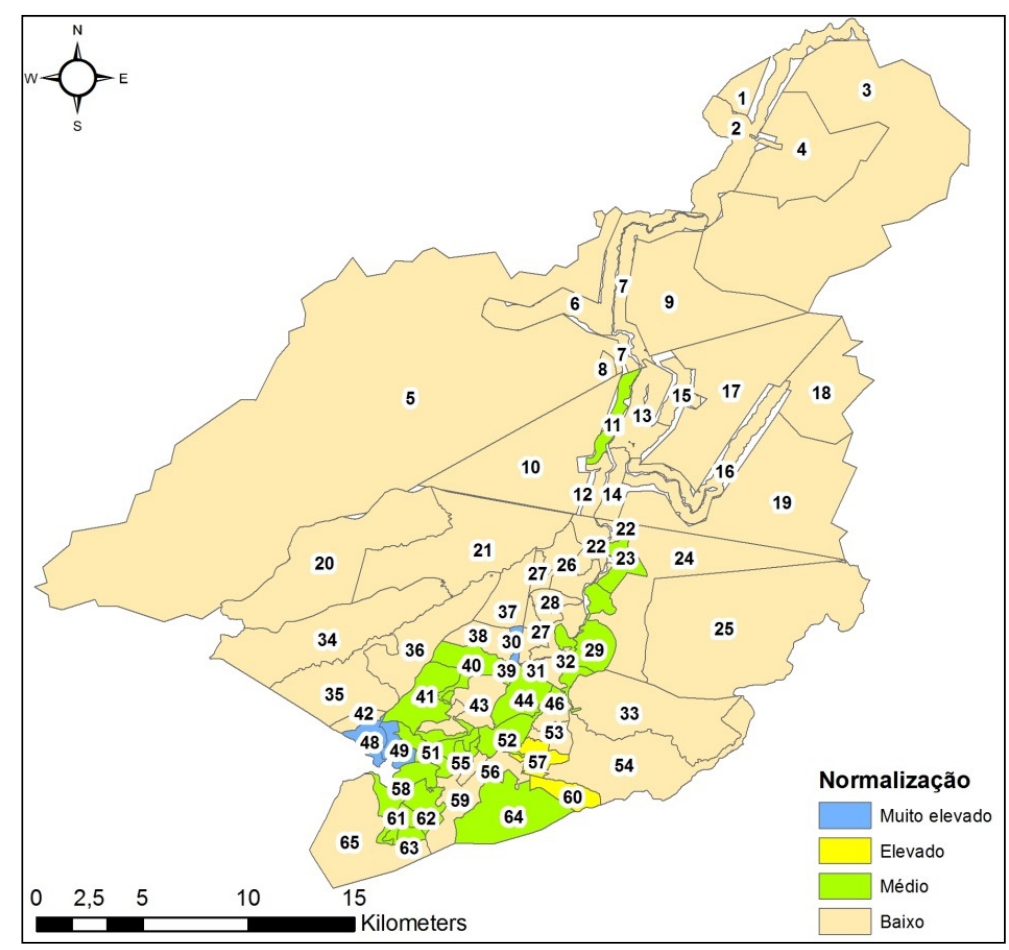

Fonte: elaboração própria 
Figura 14. Acessibilidade integral inter-regional proveniente do transporte coletivo

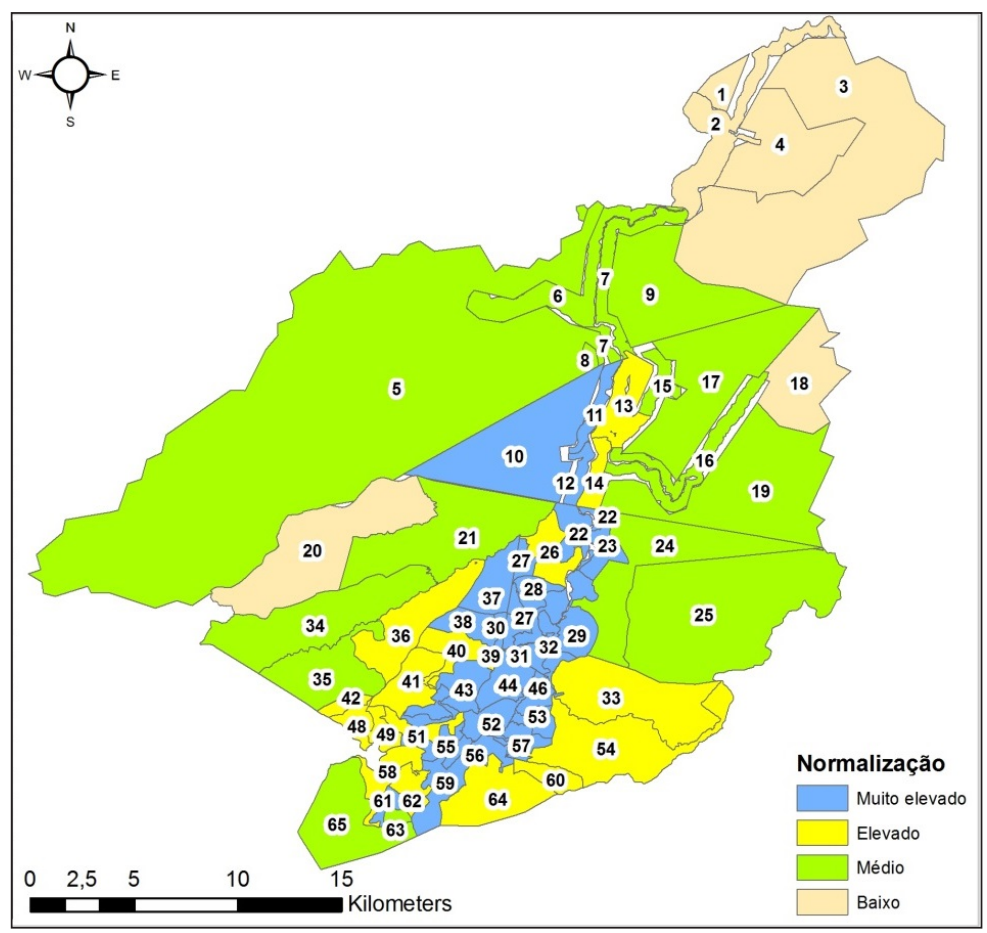

Fonte: elaboração própria

Figura 15. Frequência média semanal do transporte coletivo por ônibus

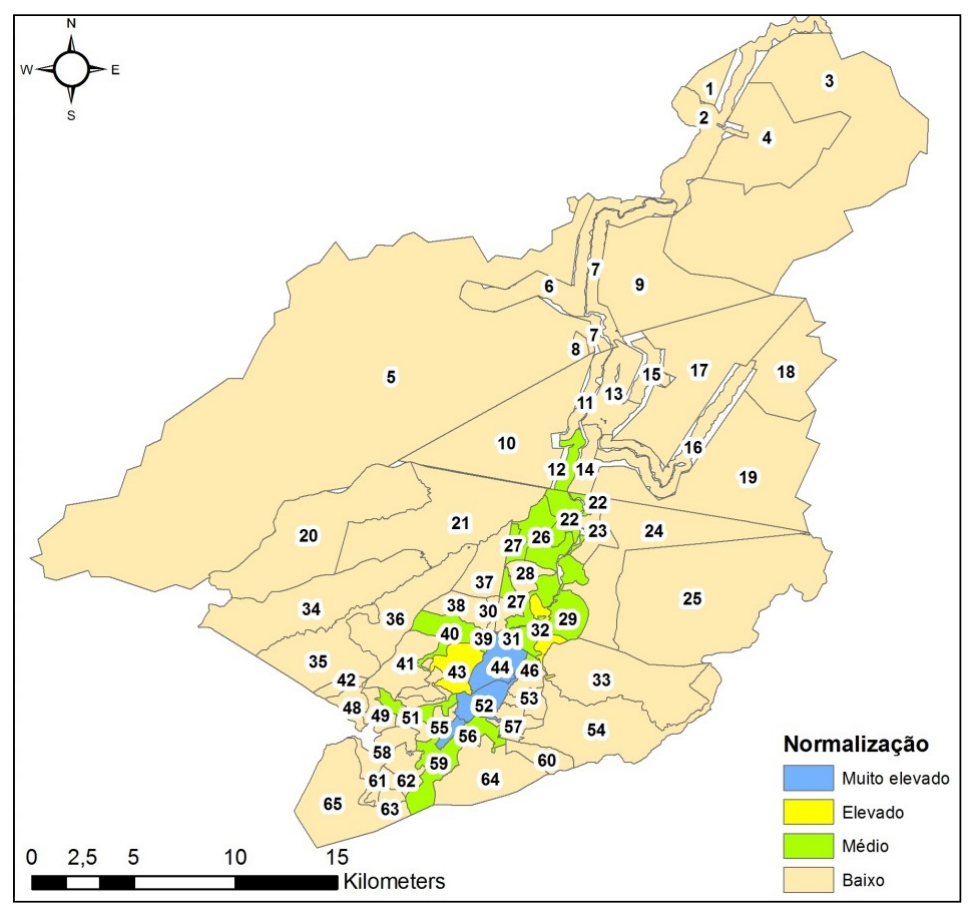

Fonte: elaboração própria 
O indicador de frequência média semanal (figura 15), do transporte coletivo por ônibus, calculada, através do headway (intervalo entre viagens), tem com intuito avaliar o seu nível de serviço. Este indicador já apresenta uma classificação baixa para a maioria das unidades espaciais da cidade, com um desempenho médio nos distritos de Petrópolis e Cascatinha.

O indicador de acessibilidade integral inter-regional (figura 16), ao centro de emprego é função das distâncias percorridas, através do sistema viário, de uma UEA para a unidade espacial de análise Centro (52). Este indicador apresenta um desempenho favorável ao deslocamento ao Centro, a partir dos distritos de Petrópolis, Cascatinha e Itaipava, se comparada ao indicador de disponibilidade de estabelecimentos comerciais e industriais, concentrado em somente duas unidades.

Figura 16. Acessibilidade relativa inter-regional ao centro de emprego

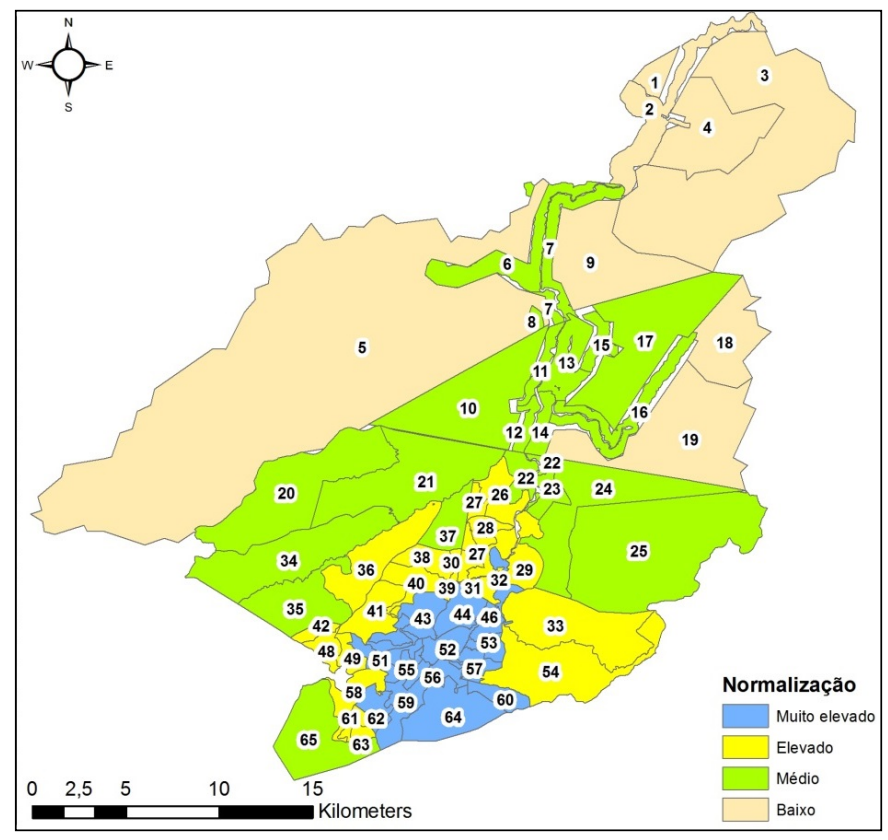

Fonte: elaboração própria

O indicador normalizado de disponibilidade de estabelecimentos de educação (figura 17) consiste no somatório dos estabelecimentos de creche, escola municipal e particular e de faculdade. Este indicador apresenta classificação baixa para a maioria das unidades espaciais de análise, com uma classificação muito elevada somente na área central.

$\mathrm{O}$ indicador de disponibilidade de estabelecimentos que permitem o alargamento das liberdades humanas (figura 18) consiste no somatório dos estabelecimentos de posto de saúde, creche, escola municipal e particular, faculdade, comércio, serviço, assistência social, hospital, universidade, museu, clube, igreja, parque, praça, quadra esportiva e teatro. Este indicador consiste no somatório de uma série de atividades relacionadas aos serviços e a equipamentos urbanos relevantes para o desenvolvimento humano. Este indicador também apresenta classificação baixa para a maioria das unidades espaciais de análise, com uma classificação muito elevada somente na área central. 
Figura 17. Disponibilidade de estabelecimentos de educação

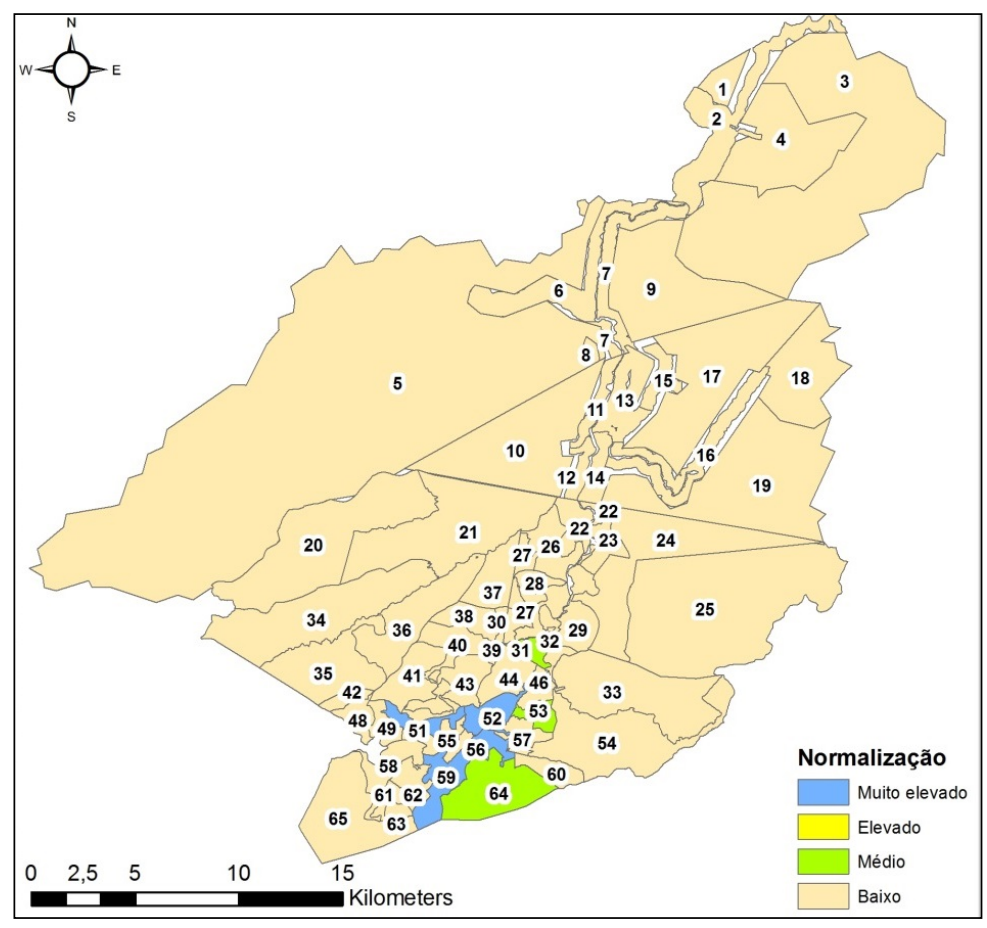

Fonte: elaboração própria

Figura 18. Disponibilidade de estabelecimentos que permitem o alargamento das liberdades humanas

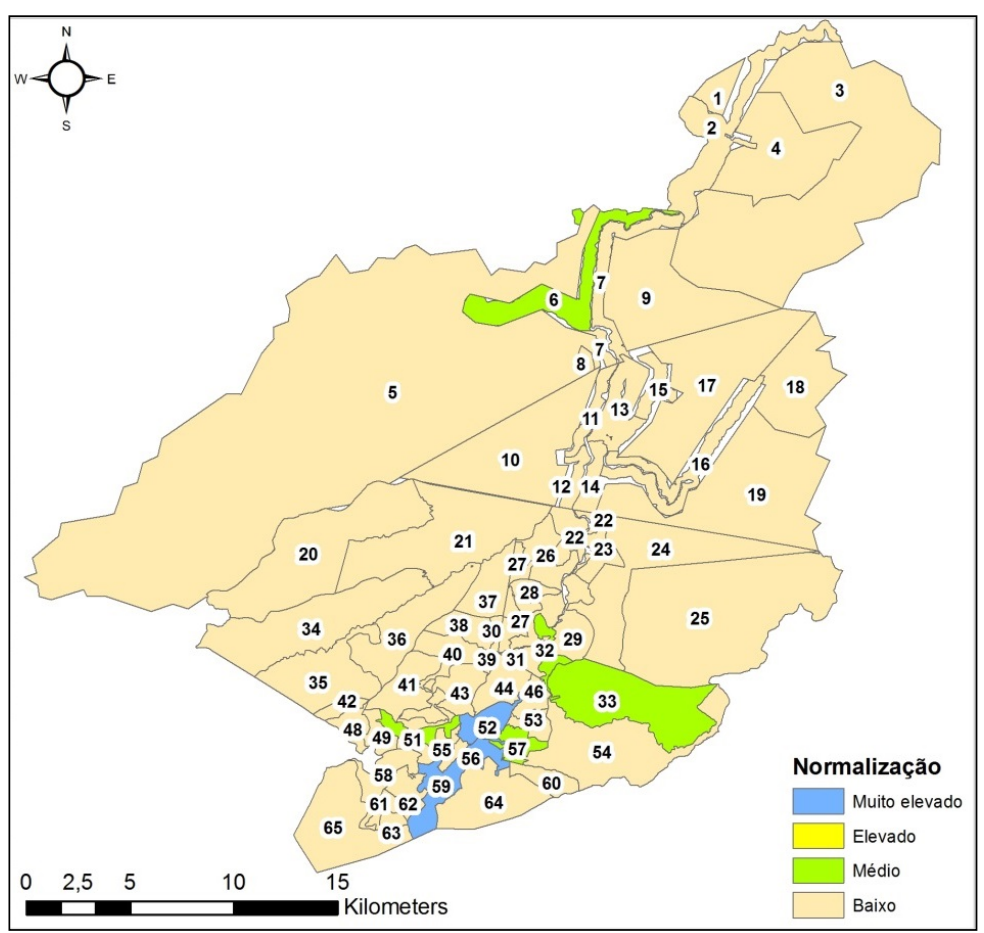

Fonte: elaboração própria 
Na tabela 4, é apresentada uma sistematização, em síntese, dos indicadores de acessibilidade apresentados e do desempenho dos seus resultados especificamente para as unidades de análise com concentração populacional e de atividades de emprego que caracteriza a formação de um núcleo central na cidade de Petrópolis. Para todas as zonas, são observados desempenhos muito elevado, elevado ou médio para quase a totalidade dos indicadores.

Tabela 4. Síntese das condições de acessibilidade para as UEA com concentração de atividades de emprego e populacional

\begin{tabular}{|c|c|c|c|c|c|}
\hline UEA/ INDICADOR & 52 & 40 & 56 & 59 & 64 \\
\hline Oferta da extensão viária & Elevado & Baixo & Muito elevado & Muito elevado & Baixo \\
\hline Cobertura espacial viária & Muito elevado & Muito elevado & Muito elevado & Muito elevado & Elevado \\
\hline $\begin{array}{c}\text { Acessibilidade integral inter-regional } \\
\text { sistema viário }\end{array}$ & Muito elevado & Muito elevado & Muito elevado & Muito elevado & Elevado \\
\hline $\begin{array}{c}\text { Extensão das vias coletoras } \\
\text { pavimentadas }\end{array}$ & Muito elevado & Muito elevado & Muito elevado & Muito elevado & $\begin{array}{c}\text { Muito ele- } \\
\text { vado }\end{array}$ \\
\hline $\begin{array}{c}\text { Extensão das vias locais } \\
\text { pavimentadas }\end{array}$ & Médio & Médio & Baixo & Baixo & Médio \\
\hline $\begin{array}{c}\text { Acessibilidade integral inter-regional } \\
\text { transporte coletivo }\end{array}$ & Muito elevado & Elevado & Muito elevado & Muito elevado & Elevado \\
\hline $\begin{array}{c}\text { Frequência média semanal do } \\
\text { transporte coletivo }\end{array}$ & Muito elevado & Médio & Médio & Médio & Baixo \\
\hline $\begin{array}{c}\text { Acessibilidade relativa inter-regional } \\
\text { ao centro de emprego }\end{array}$ & Muito elevado & Elevado & Muito elevado & Muito elevado & Muito ele- \\
\hline $\begin{array}{c}\text { Disponibilidade de estabelecimen- } \\
\text { tos de educação }\end{array}$ & Muito elevado & Baixo & Muito elevado & Muito elevado & Médio \\
\hline $\begin{array}{c}\text { Disponibilidade de estabelecimen- } \\
\text { tos que permitem o alargamento das } \\
\text { liberdades humanas }\end{array}$ & Muito elevado & Baixo & Muito elevado & Muito elevado & Baixo \\
\hline
\end{tabular}

UEA: Unidades Espaciais de Análise.

Fonte: elaboração própria.

Na tabela 5, é apresentado o número de unidades espaciais de análise classificadas segundo a categoria de desempenho adotada para o conjunto de indicadores analisados na cidade de Petrópolis. Está grifada em laranja a classificação predominante. Observa-se uma classificação baixa, no município para os indicadores de: oferta da extensão viária, extensão das vias locais pavimentadas, frequência média semanal, do transporte coletivo, disponibilidade de estabelecimentos de educação e disponibilidade de estabelecimentos que permitem o alargamento das liberdades humanas. Observa-se uma classificação elevada/ muito elevada para os indicadores de: cobertura espacial viária, acessibilidade integral inter-regional proveniente do sistema viário, extensão das vias coletoras pavimentadas, acessibilidade integral inter-regional transporte coletivo e acessibilidade relativa inter-regional ao centro de emprego. 
Tabela 5. Número de UEA classificadas segundo a categoria de desempenho adotada para o conjunto de indicadores analisados na cidade de Petrópolis

\begin{tabular}{|c|c|c|c|}
\hline Classificação/ Indicador & Baixo & Médio & Elevado/ Muito elevado \\
\hline Oferta da extensão viária & 47 & 10 & 8 \\
\hline $\begin{array}{c}\text { Cobertura espacial viária } \\
\text { Acessibilidade integral inter-regional, } \\
\text { v sistema viário }\end{array}$ & 29 & 0 & 56 \\
\hline Extensão das vias coletoras pavimentadas & 15 & 1 & 49 \\
\hline $\begin{array}{c}\text { Extensão das vias locais pavimentadas } \\
\text { Acessibilidade integral inter-regional } \\
\text { transporte coletivo }\end{array}$ & 43 & 17 & 53 \\
\hline $\begin{array}{c}\text { Frequência média semanal, do transporte coletivo } \\
\text { Acessibilidade relativa inter-regional ao centro } \\
\text { de emprego }\end{array}$ & 50 & 10 & 5 \\
\hline $\begin{array}{c}\text { Disponibilidade de estabelecimentos de educação } \\
\text { Disponibilidade de estabelecimentos que permitem o } \\
\text { alargamento das liberdades humanas }\end{array}$ & 59 & 3 & 56 \\
\hline
\end{tabular}

UEA: unidades espaciais de análise

Fonte: elaboração própria

Quanto à acessibilidade proveniente do sistema viário, verifica-se um desempenho elevado/ muito elevado, exceto para a pavimentação das vias locais. O mesmo desempenho pode ser observado para a distribuição das linhas do transporte coletivo que permitem o deslocamento entre as diversas unidades espaciais de análise dos cinco distritos. O mesmo desempenho já não é verificado para a frequência semanal deste. O desempenho para o deslocamento ao Centro pelo sistema viário é elevado, enquanto a distribuição de estabelecimentos de educação daqueles que permitem o alargamento das liberdades humanas é baixa para a maior parte das unidades espaciais de análise.

\section{Considerações finais}

Na cidade de Petrópolis, para o mesmo elemento da acessibilidade, o sistema viário, dependendo da medida adotada, é observado desempenho normalizado diferenciado para os indicadores. Enquanto a oferta da extensão viária apresenta um desempenho baixo, os indicadores de cobertura espacial viária e de acessibilidade integral inter-regional, também proveniente do sistema viário demonstram um desempenho muito elevado para um número expressivo de unidades espaciais de análise.

Evidencia-se que a formulação dos indicadores interfere nos resultados e nas conclusões aferidas, sendo necessário um exame de mais de um tipo de indicador de acessibilidade para não assumir considerações precipitadas. 
Os indicadores de acessibilidade de simples formulação permitem uma análise acurada do padrão de distribuição das oportunidades relacionadas ao sistema viário, ao transporte público e à dinâmica de uso e ocupação do solo no planejamento da cidade e dos sistemas de transporte, em relação aos indicadores de tudo ou nada (disponibilidade ou indisponibilidade), porque aqueles consideram as relações de proximidade entre os diferentes elementos e as interações de deslocamento provenientes do sistema de transporte para alcançar as oportunidades provenientes da distribuição das atividades do uso do solo.

Ainda que a acessibilidade integral inter-regional proveniente do transporte coletivo apresente um elevado desempenho na cidade, a frequência média semanal já apresenta uma classificação baixa para a maioria das unidades espaciais da cidade. Estratégias relacionadas a este indicador para reduzir as elevadas taxas de crescimento de motorização por veículo individual motorizado, observadas no município, devem ser analisadas, almejando-se alcançar melhores condições de mobilidade na cidade.

Recomenda-se a análise de outros indicadores do nível de serviço e de infraestrutura relacionados ao transporte coletivo, tais como a taxa de ocupação dos ônibus e a disponibilidade de calçadas e de ciclovias e de infraestrutura de pontos de ônibus para uma maior adesão ao transporte coletivo, dados ainda indisponíveis quando da realização deste trabalho.

A distribuição do número de habitantes evidencia uma distribuição urbana formada por um núcleo habitacional, onde está concentrado o maior número de habitantes, como pode ser observado na figura 8, núcleo este consolidado desde 1956 (figura 1). Em todas as outras unidades espaciais de análise, observa-se uma classificação baixa para o número de habitantes (figura 8) e a maior parte desta população (65\%) se distribui em até $10 \mathrm{~km}$ do Centro (tabela 2).

Contata-se que o Centro (UEA 52) apresenta classificação média para o número de habitantes e muito elevada para o número de empregos, representando uma área de convergência habitacional e de empregos na cidade. O uso do solo misto (residencial e comercial) e a ocupação concentrada da população com atividades comerciais, educacionais e daquelas que permitem o alargamento das atividades humanas nesta unidade espacial de análise contribuem para a utilização do transporte não motorizado e público, uma condição almejada no planejamento urbano das cidades.

As unidades espaciais de análise onde estão concentrados os centros de empregos (Centro e retiro 2) e o número de habitantes do município (Siméria/ Alto da Serra/ Castelânea/ Saldanha Marinho, Coronel Veiga/ Val Paraiso e Chácara Flora/ Castelânea/ Alto da Serra), como apresentado na tabela 4 dispõem de uma classificação de acessibilidade muito elevada e elevada para a maior parte dos indicadores de acessibilidade analisados, apresentando condições de transporte e uso e ocupação do solo favorável ao alcance das atividades e para o desenvolvimento urbano de áreas às quais é atribuído especial atenção no planejamento da cidade.

Assim, o núcleo urbano da cidade de Petrópolis além de sua importância histórica e de sua diversidade ambiental e ecológica (área de proteção ambiental) dispõe de excelente condição de acessibilidade proveniente do sistema de transporte e das atividades do uso e da ocupação do solo, representando uma área especial de planejamento e desenvolvimento urbano das cidades brasileiras. 
A distribuição espacial desigual da acessibilidade, proveniente da oferta do sistema de transporte e da facilidade de acesso às atividades do uso do solo presente nas cidades brasileiras também pode ser observada para metade dos indicadores analisados, na cidade de Petrópolis como apresentado na tabela 5.

Os resultados da caracterização da acessibilidade proveniente da distribuição do sistema de transporte e da dinâmica de ocupação municipal na cidade Imperial de Petrópolis, localizada no Estado do Rio de Janeiro, ora evidenciam indicadores que contribuem para a justa distribuição das vantagens territoriais provenientes do sistema viário e do transporte coletivo e do deslocamento ao Centro de emprego e ora demonstram uma desigualdade territorial, para as condições das vias locais, para a frequência do transporte público e para o alcance das atividades educacionais e daquelas que permitem o alargamento das liberdades humanas, tais como posto de saúde, creche, escola municipal e particular, faculdade, comércio, serviço, assistência social, hospital, universidade, museu, clube, igreja, parque, praça, quadra esportiva e teatro.

Os resultados dos indicadores que traduzem a desigualdade territorial entre o núcleo urbano e o restante do município contribuem para um planejamento de estratégias específicas, que precisam ser colocadas na pauta de discussão dos planos diretores da cidade e de mobilidade urbana. Somente a discussão democrática entre os diversos atores envolvidos nesta disputa territorial (centro-periferia), com base em indicadores de acessibilidade (em detrimento da análise somente de dados que indicam a disponibilidade ou indisponibilidade) pode legitimar a necessidade de uma distribuição equânime da acessibilidade em todo o território municipal, considerando a atual concentração na distribuição populacional e das atividades do uso do solo num núcleo urbano já provido de acessibilidade.

E o presente trabalho avança ao contribuir com subsídios para esta discussão, com a apresentação da viabilidade de aplicação de indicadores de acessibilidade de formulação simples e de fácil compreensão e especificamente, para a cidade de Petrópolis, com a análise da distribuição do benefício territorial proveniente do sistema de transporte e das atividades do uso e ocupação do solo.

\section{Referencias}

ANTP (2006). Panorama da Mobilidade Urbana no Brasil: Tendências e desafios. São Paulo, BNDES, vol. 3.

Bertolini, L., Clercq, F. \& Kapoen, L. (2005). Sustainable accessibility: a conceptual framework to integrate transport and land use plan-making. Two test-applications in the Netherlands and a reflection on the way forward. Transport Policy, 12(3), 207-220.

CEPERJ (2010). Bases de dados do município de Petrópolis, Centro de Estatísticas, Estudo e Pesquisas da Fundação Centro Estadual de Estatísticas, Pesquisas e Formação de Servidores Públicos do Rio de Janeiro, 1 CD-ROM.CPTRANS (2006). Mapa cadastral do município, arquivos do Autocad (dwg), Companhia Petropolitana de Trânsito e Transporte, Arquivo eletrônico [mensagem pessoal]. Mensagem recebida por izamachado@cptrans.com.br. Data: 11/01/2007. Disponível em: https://1drv.ms/f/s!ArTT1KK4QhaWha16djQea3EiWSsS_Q. Acesso em: 31/05/ 20018. 
CPTRANS (2010). Site permanente, Petrópolis, Companhia Petropolitana de Transito e Transporte. Disponível em: http://www.petropolis.rj.gov.br/cpt/index.php/horarioseitinerarios/ empresas.ht; http://www.petropolis.rj.gov.br/cpt/index.php/horarios-e-itinerarios/terminais-de-integracao.html; http://www.petropolis.rj.gov.br/cpt/index.php/horarios-e-itinerarios/linhas-centro-historico.html; http://www.petropolis.rj.gov.br/cpt/index.php/horarios-e-itinerarios/linhas-executivas.html; http://www.petropolis.rj.gov.br/cpt/index.php/ horarios-e-itinerarios/linhas-interbairros.html; http://www.petropolis.rj.gov.br/cpt/index. php/horarios-e-itinerarios/linhas-noturnas.html. Acesso em: 31/05/2018.

Cunha, M. T. da, MAIA, M. L., Lima Neto, e O. C. da C. (2004). Acessibilidade, Transporte e Reestruturação Urbana. Em A. Brasileiro, W. Kraus Jr. Anais da ANPET - Congresso de Pesquisa e Ensino em Transportes (XVIII, vol. 1, pp. 748-759). Florianópolis, SC.

Delgado, J. P. (2002). Gestão e Monitoração da Relação entre Transporte e Uso do Solo Urbano Aplicação para a cidade do Rio de Janeiro. Tese de D.Sc., Engenharia de Transportes, COPPE/ UFRJ, Rio de Janeiro, RJ.

Ferronatto, L. G. e Michel, F. D. (2007). Índice de acessibilidade por transporte coletivo. Anais da ANPET - Congresso de Pesquisa e Ensino em Transportes, XXI, Rio de Janeiro, RJ, Brasil, Nov., 1 CD-ROM.

Fundação COPPETEC (2006). Definição da Concepção e da Estrutura Metodológica de um Modelo Nacional de Transporte para o Brasil: Concepção, estrutura e metodologia de um sistema de análise de estratégias de transporte no Brasil. Ministério dos Transportes, Rio de Janeiro, 30/01/2006.

Goto, M. (2000). Uma análise de acessibilidade sob a ótica da equidade: o caso da região metropolitana de Belém. Tese de M.Sc., Escola de Engenharia de São Carlos/USP, São Carlos, SP.

Governo do Estado do Rio de Janeiro (2003). Anuário Estatístico do Estado do Rio de Janeiro, Fundação CIDE, Centro de Informações e Dados do Rio de Janeiro, vol. 19, Rio de Janeiro, RJ, Brasil.

Governo do Estado do Rio de Janeiro (2009). Anuário Estatístico do Estado do Rio de Janeiro, Fundação CIDE, Centro de Informações e Dados do Rio de Janeiro, vol. 25, edição eletrônica, Rio de Janeiro, RJ, Brasil, 1 CD-ROM.

Halden, D. (2002). Using accessibility measures to integrate land use and transport policy in Edinburgh and Lothians. Transport Policy, 9(4), 313-324.

Henrique, C. S. e Loureiro, C. F. (2005). Caracterização espacial da acessibilidade dos usuários do sistema integrado de transporte de Fortaleza. Em: A. Brasileiro, O. C. Lima Neto e M. E. Maia (eds.), Anais da ANPET - Congresso de Pesquisa e Ensino em Transportes (XIX, vol. 1, pp. 325-337). Recife, PE.

Hutchinson, B. G. (1979). Princípios de Planejamento dos Sistemas de Transporte Urbano. Rio de Janeiro, Editora Guanabara Dois S.A.

IBGE (2002). Petrópolis - RJ. Em Censo Demográfico (2000). Resultados do Universo. Instituto Brasileiro de Geografia e Estatística, Rio de Janeiro. (série base de informações por setor censitário). 
IBGE (2004). Indicadores de desenvolvimento sustentável - Brasil, [s.I], Instituto Brasileiro de Geografia e Estatística, 1 CD-ROM. Disponível em: <https://ww2.ibge.gov.br/home/geociencias/recursosnaturais/ids/ids_2004.shtm> Acesso em: 31/05/ 2018.

IBGE (2018). Petrópolis/ Rio de Janeiro/ Brasil, [s.I], Instituto Brasileiro de Geografia e Estatística. Disponível em: < https://cidades.ibge.gov.br/brasil/rj/petropolis/historico>. Acesso em: 31/05/ 2018.

Karst, T. G. e Wee, B. (2004). Accessibility evaluation of land-use and transport strategies: Review and research directions. Journal of Transport Geography, 12(2), 127-140. Disponível em: https://www.sciencedirect.com/science/article/pii/S0966692303000607. Acesso em: $31 / 05 / 2018$.

Lemos, D. S. da, e C. P. da S. (2004). Análise das relações existentes entre acessibilidade, mobilidade e desenvolvimento urbano: o caso da cidade do Rio de Janeiro. Tese de M. Sc., Engenharia de Transporte, COPPE/UFRJ, Rio de Janeiro, RJ.

Lemos, D. S. da, e C. P. da S. (2011). Análise das relações existentes entre a acessibilidade e o desenvolvimento no município de Petropolis. Tese de D.c., Engenharia de Transportes, COPPE/ UFRJ, Rio de Janeiro, RJ.

Litman, T. (2007). Evaluating Accessibility for Transportation Planning. Canadá, Victoria Transport Policy Institute.

Olaru, D., Smith, N. e Ton, T. (2005). "Activities, accessibility and mobility for individual and households". Em: BREBIA, C. A., WADHWA L. C. (ed.). Urban Transport XI: Urban Transport and the Environment in the 21st Century, 373-383, Algarve, Portugal, April/ 2005. Southhampton, WIT.

Pasaogullari, N. e Doratti, N. (2004). Measuring accessibility and utilization of public spaces in Famagusta. Cities, 21(2), 225-232.

Pegoretti, M. S. e Sanches, S. da P. (2005). Definição de um indicador para avaliar a acessibilidade dos alunos da zona rural às escolas de zona urbana. Em A. Brasileiro, O. Lima Neto e M. Maia (eds.), Anais do XIX Congresso de Pesquisa e Ensino em Transportes, 1, 605-616, Recife, PE.

Pires, F. M. (2000). Uma contribuição metodológica para a avaliação dos Padrões de Acessibilidade em Redes Rodoviárias. M. Sc., Programa de Engenharia de Transportes/ COPPE, Universidade Federal do Rio de Janeiro, Rio de Janeiro, RJ.

PNUD (2009). Relatório do Desenvolvimento Humano 2009: ultrapassar barreiras: mobilidade e desenvolvimentos humanos. Programa das Nações Unidas, Nova York, Edições Almedina. Disponível em: <http://hdr.undp.org/sites/default/files/hdr2009-portuguese-summary. pdf>. Acesso em: 31/05/ 2018.

Prefeitura Municipal de Petrópolis (2009). Site permanente, Petrópolis, Disponível em: http:// www.petropolis.rj.gov.br/pmp/index.php/cidadao/informacoes/seguranca-publica.html Acesso em: 31/05/2018.

Puebla, J. G. e Melhorado, A. M. (2006). Medición de Efectos de desbordamiento de las Infraestructuras de Transporte a partir de Indicadores de Accesibilidad. Congreso Panamericano de Ingeniería de Tránsito y Transporte, XIV, Las Palmas de Gran Canária, Espanha, 1 CD-ROM. 
Raia Jr., A. A. (2000). Acessibilidade e mobilidade na estimativa de um índice de potencial de viagens utilizando redes neurais artificiais e sistemas de informações geográficas. Tese de D. Sc., Escola de Engenharia de São Carlos/USP, São Carlos, SP.

Sales Filho, L. de H. (1996). O uso de indicadores de acessibilidade na avaliação de redes estruturais de transporte urbano. Tese de D. Sc., Programa de Engenharia de Transportes/COPPE/ UFRJ, Rio de Janeiro, RJ.

Sanches, S. da P., Ferreira, M. A. G. e De Deus, L. R. (2007). Avaliação de indicadores de oferta de transporte coletivo. CLATPU - Congresso Latinoamericano de Transporte Público y Urbano, XIV, Rio de Janeiro, RJ, Brasil, 1 CD-ROM.

Santos, C. N. F. (1990). O uso do solo e o município, 3 ed. Rio de Janeiro, IBAM. Textos de Administração Municipal, 2.

SEF (2009). Levantamento de Contribuintes de Petrópolis, planilha do Microsoft Excel, Secretaria Estadual de Fazenda, Arquivo eletrônico. Mensagem recebida por pela instituição. Data: 31/05/2009. Disponível em: < https://1drv.ms/f/s!ArTT1KK4QhaWha16djQea3EiWSsS_Q>. Acesso em: 31/05/ 20018.

Sinha, K. e Labi, S. (2007). Transportation decision making: principles of project evaluation and programming. United States of America, John Wiley \& Sons, Inc.

Souza, A. R. M. F. de (1990). Mobilidade Urbana: estudo do caso da cidade de Salvador - Bahia. Tese M. Sc. Programa de Engenharia de Transportes, COPPE/UFRJ, Rio de Janeiro, RJ.

Vasconcellos, E. A. (2000) Transporte urbano, espaço e equidade: análise das políticas públicas. $3^{a}$ ed., São Paulo, Anablume.

Villaça, F. (2001). Espaço intra-urbano no Brasil. 2a ed., São Paulo, Studio Nobel, FAPESP, Lincoln Institute. 